\title{
Psychosocial support needs of Slovak breast cancer survivors one and three years after breast conserving surgery
}

\author{
Bencova $\mathrm{V}^{1}$, Krajcovicova $\mathrm{I}^{1}$, Bella $\mathrm{V}^{2}$, Krcmery $\mathrm{V}^{3}$ \\ Ist Clinic of Oncology, Faculty of Medicine, Comenius University, Bratislava, Slovakia. \\ viera.bencova@hafling.sk
}

\begin{abstract}
Objective: To assess psychosocial support needs among Slovak breast cancer survivors treated by breast conserving surgery.

Methods: Patients responded the EORTC QLQ 30.3 questionaire and the self-elaborated BCPN (Breast Cancer Psychosocial Needs) questionaire one and three years after breast conserving surgery (BSC) and modified radical mastectomy (MRM).

Results: Assessment of psychosocial distress related to breast cancer treatment have shown a remarkable time-realted increase in scores of emotional distress symptoms among breast cancer patients treated with breast-conserving surgery. Analysis of psychosocial support needs of these patients has shown, that a substantial part of breast cancer survivors are feeling inadequate benefitial psychosocial support from health care providers (informational support), social oncology workers, and psychologists (emotional support). Insufficient targeted psychosocial support involved individual as well as group intervention (provided by breast cancer patients surviving the disease for long time). Conclusion: Unmet psychosocial needs from health care providers has been percieved as a major factor harming patients ability to cope with the disease and to maintain their family, marital and social functioning (Tab. 2, Fig. 1, Ref. 22). Full Text in PDF www.elis.sk.

Key words: breast cancer, psychosocial distress, quality of life, unmet needs in psychosocial support.
\end{abstract}

Like in other European countries, breast cancer patients represent the major group of cancer survivors in the Slovak Republic. Within the 5,6 million population, more than 2000 patients with newly diagnosed and treated breast cancer will each year enlarge the number of survivors suffering from the disease and its aggressive treatment. As the rate of early stage breast tumors treated by curative breast conserving surgery (BCS) and radiotherapy is constantly raising, and the five years survival is reaching $65 \%$ (1), there is an urgent need to provide these patients with longterm care, which is generally focused to clinical issues including treatment outcome, treatment complications, disease-free interval, and survival rate. Much less attention is payed to the psychosocial burden related to breast cancer diagnosis and treatment. Overal emotional disorder expressed by enhanced anxiety and depression, body image disruption, disorders in family, sexual and social functioning, hopelessness and frustration - symptoms negatively influencing the health-related quality of life of breast cancer survivors - are frequently underestimated (2).

In the last three decades vast evidence have been accumulated demonstrating that women experiencing breast cancer are emo-

${ }^{1}$ Ist Clinic of Oncology, Faculty of Medicine, Comenius University, Bratislava, Slovakia, ${ }^{2}$ St. Elisabeth Institute of Oncology, Bratislava, Slovakia, and ${ }^{3}$ St. Elisabeth University of Health and Social Sciences, Bratislava, Slovakia

Address for correspondence: V. Bencova, $\mathrm{PhD}$, Ist Clinic of Oncology, Faculty of Medicine, Comenius University, Heydukova 10, SK-812 50 Bratislava, Slovakia.

Phone: +321.2.32249 416, Fax: +421.2.32249 415 tionally affected long after diagnosis and treatment, mainly due to concerns about cancer recurrence, fatigue, body image disruption, sexual functioning, and anxiety from repeated checkups (3-6). Fallowfield and coworkers (7), Ganz and coworkers (4) and others showed that besides mastectomized patients, early stage breast cancer patients treated with breast conserving surgery are suffering from anxio-deressive syndrome years after the treatment termination.. The long-term persistence of these symptoms over months and years require professional targeted psychosocial intervention (8).

The present study was aimed at assessing the extent of psychosocial burden on the health-related quality of life of Slovak breast cancer survivors one and three years after BCS and modified radical mastectomy (MRM) followed by adjuvant radiotherapy. Along with the quality of life assessment, psychosocial intervention and support needs of these patients was investigated and statistically evaluated.

\section{Material and methods}

Patients

127 breast cancer treated patients, aged 34-78 years $( \pm 44$ years), attending the the outpatient,s mammology unit between 2006-2010 years for regular inspection were recruted into the study. From those, 81 patients previously treated for early-stage breast cancer (T1-T2a) by BCS, and 46 patients wiith advanced cancer (T2b-T3) treated by MRM were included. Only relapsefree patients without clinical symptoms of disese progression and severe comorbidity and surviving minimum three years post 
Tab. 1. Symptoms of psychosocial dysfunction in breast cancer survivors one and three years after MRM versus BCS as asssessed by the EORTC QLQ 30.3 questionaire.

\begin{tabular}{|c|c|c|c|c|c|c|c|c|c|c|c|c|c|}
\hline \multirow[t]{2}{*}{ symptoms } & \multirow[t]{2}{*}{ Item No. } & \multicolumn{2}{|c|}{$\begin{array}{c}\text { MRM } \\
\text { (1 year) }\end{array}$} & \multicolumn{2}{|c|}{$\begin{array}{c}\text { BCS } \\
\text { (1 year) }\end{array}$} & \multicolumn{2}{|c|}{$\begin{array}{c}\text { MRM } \\
\text { (3 years) }\end{array}$} & \multicolumn{2}{|c|}{$\begin{array}{c}\text { BCS } \\
\text { (3 years) }\end{array}$} & \multicolumn{2}{|c|}{$\begin{array}{l}\text { MRM3/ } \\
\text { MRM1 }\end{array}$} & \multicolumn{2}{|c|}{$\begin{array}{l}\mathrm{BSC} 1 / \\
\mathrm{BSC} 1\end{array}$} \\
\hline & & RS & LT & $\mathrm{RS}$ & LT & $\mathrm{RS}$ & LT & $\mathrm{RS}$ & LT & ratio & $\mathrm{p}$ & ratio & $\mathrm{p}$ \\
\hline Anxiety, nervousess & 21,22 & 2.5 & 50.0 & 2.1 & 36.6 & 2.6 & 53.3 & 3.2 & 73.3 & 1.07 & NS & 2.03 & $<0.05$ \\
\hline Uncertainity & 20,25 & 3.2 & 73.3 & 1.9 & 30.0 & 2.5 & 50.0 & 2.1 & 36.6 & 0.68 & NS & 1.02 & NS \\
\hline Irritability & 23 & 2.7 & 56.6 & 2.0 & 33.3 & 2.4 & 46.6 & 2.4 & 46.6 & 0.82 & NS & 1.39 & $<0.05$ \\
\hline Financial concerns & 28 & 2.5 & 50.0 & 2.2 & 40.0 & 1.9 & 33 & 1.6 & 20.0 & 0.67 & NS & 0.50 & NS \\
\hline Fatigue & $4,10,12$ & 2.6 & 53.3 & 2.0 & 33.3 & 3.0 & 66.6 & 2.0 & 33.3 & 1.24 & NS & 1.00 & NS \\
\hline Body image & $27,39,42$ & 2.5 & 50.0 & 1.7 & 23.3 & 2.0 & 33.3 & 1.2 & 6.6 & 0.66 & NS & 0.28 & NS \\
\hline Pain & 9,19 & 2.2 & 40.0 & 2.0 & 33.3 & 2.5 & 50.0 & 1.5 & 16.6 & 1.25 & NS & 0.49 & NS \\
\hline Sexual functioning & $26,44-46$ & 1.9 & 30.0 & 1.2 & 6.6 & 1.7 & 23.3 & 1.1 & 3.3 & 0.77 & NS & 0.50 & NS \\
\hline Lonelessness & 24 & 1.6 & 20.0 & 1.2 & 6.6 & 2.1 & 36.6 & 1.5 & 16.6 & 1.83 & $<0.05$ & 2.51 & $<0.05$ \\
\hline Future perspective & 43 & 1.9 & 30.0 & 1.1 & 3.3 & 2.8 & 60.0 & 1.9 & 30.0 & 2.00 & $<0.05$ & 2.71 & $<0.05$ \\
\hline
\end{tabular}

RS - Raw score 1 - 4 (not at all - very much) LT - Linear transmission (1 - 100) SD - standard deviation, P - confidence NS - not significant. Higher score means higher level of symptomatology

Tab. 2. Psychosocial support needs of breast cancer survivors one and three years of breast conserving surgery (Breast Cancer Psychosocial Needs -BCPN - questionaire)*.

\begin{tabular}{|c|c|c|c|c|c|}
\hline \multirow[t]{3}{*}{ Support requirements } & \multicolumn{2}{|c|}{ years after BCS } & \multirow[t]{3}{*}{ Diff. } & \multirow[t]{3}{*}{$\mathrm{SD}$} & \multirow[t]{3}{*}{$\mathrm{p}$} \\
\hline & one & three & & & \\
\hline & \multicolumn{2}{|c|}{ mean score } & & & \\
\hline \multicolumn{6}{|c|}{ 1. I would welcome more information about my disease } \\
\hline From the doctor & 2.8 & 1.9 & -0.3 & 0.63 & NS \\
\hline From health care providers (nurses) & 2.0 & 1.2 & -0.8 & 0.56 & NS \\
\hline From experienced oncology social worker & 1.8 & 1.6 & -0.2 & 0.14 & NS \\
\hline From psychologist & 1.9 & 2.0 & +0.1 & 0.07 & NS \\
\hline From a breast cancer survivor & 3.6 & 2.2 & -1.4 & 0.99 & $<0.05$ \\
\hline \multicolumn{6}{|c|}{ 2. I would prefer more counselling about my fear and concerns } \\
\hline From my doctor... & 2.4 & 2.6 & +0.2 & 0.14 & NS \\
\hline From health care providers & 2.8 & 1.9 & -0.3 & 0.63 & NS \\
\hline From oncology social worker & 2.0 & 3.5 & +1.5 & 1.06 & $<0.05$ \\
\hline From psychologist & 2.0 & 3.0 & +1.0 & 0.70 & NS \\
\hline From a breast cancer survivor & 3.0 & 3.2 & +0.2 & 0.14 & NS \\
\hline From a priest & 2.1 & 1.8 & -0.3 & 0.63 & NS \\
\hline \multicolumn{6}{|l|}{ 3. I would need more understanding of my suffering } \\
\hline From my family members & 1.8 & 2.0 & +0.2 & 0.14 & NS \\
\hline From my husband/partner & 1.9 & 1.6 & -0.3 & 0.63 & NS \\
\hline From the health care personnel & 1.8 & 1.2 & -0.4 & 0.42 & NS \\
\hline \multicolumn{6}{|c|}{ 4. I feel a mediated talk about my sorrow will be helpful when adressed } \\
\hline To my husbad & 2.0 & 1.1 & -0.9 & 0.63 & NS \\
\hline To my employer & 1.2 & 1.4 & +0.2 & 0.14 & NS \\
\hline
\end{tabular}

Score 1 - 4 (not at all - very much), raw score calculated according to EORTC QLQ - C30 manual, * the questonaire was responded after the ,who- is- who“ role and function has been explained, NS - not significant

surgery were eleigible. The inclusion criteria included the entire participation in the survey and full completion of the questionaires. The health-related quality of life, psychosocial morbidity, social status and unmet needs for psychosocial intervention and support were investigated in both groups of breast cancer survivors one year (+-3,4 months) and three years (+-4,5 months) after surgery by means of EORTC quality of life and BCPN psychosocial support need questionaires. The results were statistically evaluated by means of the Excell Functions software program.

\section{Quality of life and psychosocial status assessment}

Psychoscial distress and quality of life of breast cancer survivors was tested by means of standardized European Organiza- tion for Rosearch and Treatment of Cancer questionaries. Patients responded the EORTC Quality of Life C30.3 questionaire (QLQ C30.3), a 23-item questionaire comprised of nine domains: physical symptoms, functioning (9-11), cognitive, emotional and social status, fatigue, pain, nausea and vomiting $(9,10)$. The breast cancer-specific QLQ-BR23 module was employed in an attempt to compare clinical variables (therapeutic side-effects) with psychosocial items (body image, sexual functioning, sexual enjoyment, and perception of future perspective (11)). The self designed Breast Cancer Psychosocial Needs (BCPN) questionaire (Table 2) is composed of 16 items in four sections (informational, emotional, social, and mediated intervention) analysing unmet psychosocial support needs of breast cancer survivors at desired time of investigation. The 1-4 Likert scale (not et al - very much) has been 


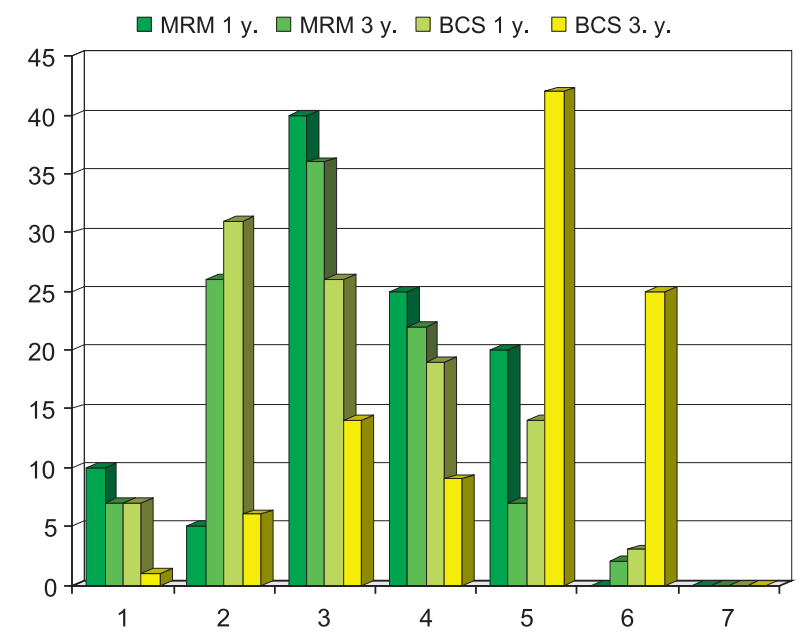

Fig. 1. Quality of life assesment among breast cancer patients surviving one and three years after breast conserving surgery versus modified radical mastectomy.

used to weigh the psychosocial morbidity symptomatology and needs of psychosocial support. The results were recalculated and statistically evaluated according to the EORTC QLQ evaluation manual (10). Although the validity of the BCPN questionaire was not yet internationally evaluated, its reliability index (Cronbach's alpha) in this study was 0.82 .

\section{Results}

Time-related difference of health-related quality of life in breast cancer survivors after BCS.

The health-realted QoL of breast cancer survivors one and three years after BCS versus MRM is presented in Figure 1. Using the 1-7 linear scale (very poor - excellent, QLQ-C30.3, item 29 ), the survey showed that one year after BCS breast cancer survivors scored rather low and uniformly with those being after MRM (2-4 ,poor - rather poor"). However, clear differences in scoring among patients surviving from BCS three years after surgery were observed (Fig. 1). In comparison with patients surviving one year after BCS, almost $70 \%$ patients surviving three years after BCS scored considerably higher between 4-5 (rather good - good) providing improvement in their quality of life. In comparison, great majority of patients surviving three years after MRM reported their quality of life low. Despite the fact that the BCS-treated breast cancer patients survived three years after surgery without any sign of tumor reccurence, at least $30 \%$ survivors from this group of patients considered their health-related quality of life as poor It is to note, that none of the BCS-treated breast cancer survivors considered their quality of life to be excellent.

\section{Psychosocial dysfunction scores in BCS-treated breast cancer patients}

The extent of psychosocial distress in BCS-treated breast cancer patients surviving one and three years after surgery as assessed by the EORTC QLQ C3O.3 questionaire is presented in Table 1.
In the control MRM-treated patients, the emotional distress was expressed in high scores of anxiety, irritability, and uncerntainty, body image perception along with fatigue and pain as detected one year after surgery. High scores of psychosocial burden did not change significantly after three years survival. Patients surviving one year after BCS scored considerably lower. However, three years after BCS, significant increase in scores of anxiety, irritability, lonelesness, and negative perspective perception has been observed. Comparison of psychosocial morbiodity scores of both, MRM - as well as BCS - treated patients indicate that the psychosocial burden is harming quality of life of breast cancer survivors regardless the extent of surgical intervention. Moreover, enhanced scores of emotional distress symptoms in BCS - treated survivals shold be considered as a warning signal to health care providers and psychsocial workers of an urgent need to pay more attention to unmet psychosocial needs of these patients. It is to note, that assessment of breast cancer-related site effects and treatment outcomes in patients treated by BCS have shown that clinical symptoms related to breast cancer and its treatment have limited impact onto quality of life regardless survival time.

\section{Psychosocial support needs of BCS-treated breast cancer sur-} vivors

By answering the BCPN questionaire (Tab. 2) a great number of responders reported an inadequate information support from health care providers. The BCS-treated breast cancer survivors would expect more information about the

disease and its treatment, the treatment outcomes and patient,s perspective. Moreover, more emotional support is expected from psychosocial workers and psychologists in helping patients to diminish disease- and treatment-associated distress, to improve marital and family relations and their social well-being. Unadressed psychosocial problems involved the lack of mediated talk about patient,s sorrow with patient,s husband and family members as well as an organized discussion with breast cancer patients surviving long time after treatment of the very same disease.

\section{Discussion}

Emotional distress related to diagnosis and treatment of breast cancer may have profound negative consequences onto patient, $\mathrm{s}$ ability to cope with the disease, to adhere to the treatment regimes, to engage in steps improving role functioning and social well-being (12). Although the psychosocial dimension of cancer is well documented (13-16) the oncological social work profession,s commitment to support coping capabilities and to eliminate health disparities of cancer survivors and their family members did not find substantial attention and support among health care providers (17-19) Moreover, the urgent need to identify psychosocial stressors influencing quality of life of cancer survivors, their families and members of the patient,s social network along with the need to provide patients with psychosocial intervention and treatment was until today not recognized as a factor influencing coping capabilities, treatment outcome, survival time and health-related quality of life of cancer patients $(2,5,19,20)$. According to the US gover- 
ment report, issued by the NIH Institute of Medicine (IOM, 2008), the tendency to analyze, evaluate, and eliminate psychoslogical health needs of cancer patients is the exception rather than the rule in clinical oncology. According to the report, health care providers fail to recognize and understand psychosocial needs of cancer patients and their family members. Based on recommendation indicating that meeting psychosocial needs of the cancer patient should be an integral part of cancer care, research became funded that is focused on developing performance measures for psychosocial cancer care. In the last years, the psychosocial support care became a part of cancer treatment especially in western countries.

In comparison to USA, Australia, and the majority of EU member States, Slovakia lag behind in the psychosocial care of indoor and outdoor cancer patients and their social framework, although some non-govermental organisations (Anticancer League) are putting much effort in order to improve the contemporary situation. It is to emphasize, that overloading of health care providers with clinical work, short clinic visits, insufficient financing and gaps in professional health care education do not allowe them to explore cancer patient,s emotional concerns related to the disease and its outcome $(19,20)$. This survey brought additional information indicating that nearly $30 \%$ of Slovak early-stage breast cancer patients previously treated by breast-conserving surgery indicate unmet needs of psychosocial intervention, preferably in the informational and emotional support even three years after the treatment was terminated. These findings imply that besides recovery from the treatment, psychosocial distress, harming the coping capability and quality of life, may persist or even accelerate in breast cancer survivals long after the treatment was terminated. Serious shortcommings in the recognition of psychosocial burden of cancer survivors and insufficient psychosocial intervention may negatively influence long-term clinical outcomes and the overal survival time $(21,22)$. The results of this study can be regarded as an useful signal in prompting health care providers to pay more attention to psychosocial supportive care of breast cancer survivors.

\section{References}

1. Autier P, Boniol M, LaVecchia C, Vatten L, Gavin A, Héry C, Heanue $\mathrm{M}$. Disparities in breast cancer mortality trends between 30 European countreis: retrospective trend analysis of WHO mortality database. Brit Med J 2010: 341: c3620. Doi: 10.1136/bmj.c3620.

2. Holzer B, Kemmer G, Kopp M, Moschen R, Schweighofer H, Dunser M, Margreiter R, Fleischhacker W, Sperner-Unterweger B. Quality of life in breast patients - not enough attention for long-term survivors? Psychosomatics 2001: 42: 117-123.

3. Fawzy FI, Fawzy NW, Arndt LA, Pausman R Critical review of psychosocial interventions in cancer care. Arch Gen Psychiatry 1995: 52 (2): 100-113.

4. Ganz, PA, Desmond K, Leedham B, Rowland J, Meyerowitz B, Belin T. Quality of life in long-term, disease free survivors of breast cancer: a follow-up study. J Nat Cancer Inst 2002: 94 (1): 39-49.

5. Ganz PA. Psychological ans social aspects of breast cancer. Oncol 2008: 22 (6): 246-254.
6. Montazeri A, Vahdaninia M, Harirchi I, Ebrahimi M, Khaleghi F, Jarvandi S. Quality of lifge in patients with breast cancer before and after diagnosis: an eighteen months follow-up study. Brit Med J Cancer 2008: 8: 330-337. doi: 10.1186/1471-2407-8-330

7. Fallowfield LJ, Hall A, Maguire G.P, Baum M. Psychological outcomes of different treatment policies in women with early breast cancer outside a clinical trial. Brit Med J 1999: 301: 575-580.

8. Erstmann N, Neumann M, Ommen O, Galushko M, Wirtz M, Voltz R, Hallek M, Pfaff H. Determinants and implications of cancer patients, psychosocial needs. Support Care Cancer 2009: 17 (14): 1417-1423.

9. Aaronson NK, Ahmedzai S, Bergman B, Bullinger M, Cull A. The European Organization for Research and Treatment of Cancer QLQ-C30: a quality of life instrument for use in international clinical trials in oncology. J Nat Cancer Inst 1993: 85: 365-376.

10. Fayers PM, Aaronson NK, Bjordal K, Groenvold M, Bottomley A. (on behalf of the EORTC Quality of Life Group): The EORTC Scoring Manual. 3rd Edition, Brussels, Belgium. European Organisation for Research and Treatment of Cancer Press, 2001.

11. Sprangers, M.A., Groenvold, M., Arraras, R.I., Franklin, J. teVerde, M. The European Organization for Research and Treatment of Cancer - Breast cancer-specific quality of life questionaire module: first results from a three-country field study. J Clin Oncol 1996: 14: 2756-2768.

12. Hart J. Adressing the psychosocial needs of cancer survivors Alternat. Complement Ther 2007: 13 (4): 183-186.

13. Moyer A. Psychosocial outcomes of breast-conserving surgery versus mastectomy: a meta-analytic review. Health Psychol 1997: 16 (5): 284-298.

14. Pettigrew M, Bell R, Hunter D. Influenece of psychosocial coping on survival and recurence in people with cancer systhemic review. Br Med J 2002: 325: 1166-1069.

15. Arndt V, Merx H, Stegmayer C, Ziegler H, Brenner H. Persistence of restrictions in quality of life from the first to the third year after diagnosis in women with breast cancer. J Clin Oncol 2005: 23: 4945-4953.

16. Arnd V, Stegmaier C, Ziegler H, Brenner H. Quality of life over 5 years in women with breast cancer after breast-conserving therapy versus mastectomy: a population-based study. J Cancer Res Clin Oncol 2008: 134 (12): 1311-1318.

17. Nelson R. Psychosocial health needs of cancer patients not being met. Medscape Med. News 2007 http://www.medscape.com/viewarticle/564989.

18. IOM : Consequences of unmet psychosocial needs. In: Cancer Care For The Whole Patients. The NIH Institute of Medicine (IOM) Report 2008, US Nat. Acad. Press, Washington, USA, 2008 ISBN 0-309-11108-0.

19. Bencova V, Svec J, Bella V. The role of psychosocial oncology in the health care of breast cancer survivor. Bratisl Lek Listy 2009: 110 (6): 374.

20. Bencova V, Mrazova A, Svec J. Psychosocial morbidity - an unfilled gap in undergraduate courses of medicine and nursery. Clin Soc Work 2010: $1-2: 37-46$.

21. Ferell BR, Grant MM, Funk BM, Otis-Green SA, Garcia NJ. Quality of life in breast cancer survivors: implications for developing support services. Oncol Nurs Forum 1998: 25 (5): 887-895.

22. Kroenke CH, Kubzansky LD, Schernhammer ES, Holmes MD, Kawachi I. Social network, social support, and survival after breast cancer diagnosis. J Clin Oncol 2006: 24: 1105-1111.

Received December 14, 2011. Accepted December 11, 2012. 